\title{
KRITERIA RUANG PUBLIK KALIJODO PENDUKUNG AKSESIBILITAS DAN PENINGKATAN AKTIVITAS
}

\author{
Hansen Hartoyo ${ }^{1}$, Santoni ${ }^{2}$ \\ Arsitektur, Fakultas Desain, Universitas Pelita Harapan \\ Email: ${ }^{1}$ hansen.hartoyo@gmail.com, ${ }^{2}$ santoni@ podomorouniversity.ac.id
}

\begin{abstract}
Abstrak
Ruang publik merupakan ruang untuk melakukan kegiatan sosial, ekonomi, dan budaya. Selain ruang terbuka hijau, ruang sepanjang sungai juga mempunyai potensi untuk dijadikan sebagai sebagai ruang publik. Faktanya ruang sepanjang sungai hanya digunakan untuk permukiman liar dan tidak ada penyediaan ruang publik di dalamnya. Penelitian akan berfokus pada penentuan kriteria yang dibutuhkan untuk membentuk ruang publik di sekitar bantaran sungai dalam mendukung aksesibiltas dan peningkatan aktivitas. Teori yang akan digunakan ialah prinsip kawasan terintegrasi sungai (Charles A. McLaren - A Guide to Riverfront Development) dan teori Public Space oleh Stephen Carr dan Carmona. Tapak yang akan di analisis adalah ruang publik di Kawasan Kalijodo yang berbatasan langsung dengan air. Berdasarkan kedua teori yang digabungkan, kriteria yang akan digunakan dalam menganalisis objek studi adalah kenyamanan, aktivitas, sosiabilitas dan yang ditekankan ialah akses, meliputi titik akses pedestrian, tipe dan distribusi akses universal, dan prioritas pedestrian. Berdasarkan penelitian dapat disimpulkan akses secara fisikal sudah terpenuhi dengan adanya tangga dan jembatan penghubung dari sungai, namun harus mempertimbangkan akses secara visual, menambahkan program yang spesifik agar pemetaan merata dan ditunjang dengan vegetasi yang lebih rapat untuk mendukung kenyamanan.
\end{abstract}

Kata kunci: aktivitas, aksesibilitas, ruang publik, bantaran sungai

\begin{abstract}
Title: Relation of Activity and Connectivity of Kalijodo as a Public Space

Public space is a place for social, economic and culture activity. Besides green open spaces, there are a lot of space along the river that have potential issues to be created as a public space. In fact, number of riverside are filled by slum area and there is no public space along the riparian. This research focused on the determining the chriterias of public space that support connectivity and incilining the number of activities. Theory that applied for this research is A Guide to Riverfront Development by Charles A. McLaren amd Public Space principle by Stephen Carr and Carmona. Kalijodo is one of the public space that will be studied because of its position faced in front of the river. Based on those theories, there are chitrerias that will be used to analyse the study casem which are comfort, activity, sociability, and more focus on access, including pedestrian access point, type and distribution of universal access and pedestrian priority. The result of this research could be summarised that physical access are attained by stairs and bridge that connect from river. Eventhough, Kalijodo must concern about visual access, addition of specific program to spread the activities and support by dense of vegetation to reach comfort.
\end{abstract}

Keywords: activity, accessibility, public space, riverside 


\section{Pendahuluan}

Ruang publik menurut Project for Public Spaces in New York tahun 1984

adalah area ruang terbuka yang digunakan manusia secara bersama-sama yang dapat menampung aktivitas bersama. Area ini dapat berbentuk plaza, taman, jalan, alun-alun,dll (Project 1984 dikutip Ramadhani 2015). Didalam wadah ini manusia melakukan kegiatan interaksi antar individidu, bersosialisasi, berelaksasi, ataupun melakukan kegiatan yang berkaitan dengan ekonomi (ruang tempat berjualan) dan budaya. Menurut Carr, Ruang publik merupakan suatu fasilitas/wadah tempat berlangsungnya kehidupan komunal sebuah kawasan (Carr,1992). Ruang ini bersifat dinamis dan esensial bagi pertumbuhan sebuah kawasan karena bertindak sebagai penyedia aksesibilitas yang baik, pembentuk ruang komunikasi antar penduduk dan tempat umum yang dapat menyokong aktivitas bermain dan berelaksasi.

Berdasarkan UU no 26 tahun 2007 pasal 29 menyatakan bahwa proporsi ruang terbuka hijau pada wilayah kota paling sedikit 30 (tiga puluh) persen, sedangkan proporsi ruang terbuka hijau publik sedikitnya 20 (dua puluh) persen dari luas wilayah kota. Namun faktanya, penyediaan ruang publik dalam lingkup perkotaan masih terbilang minim, hal serupa terjadi pada lingkup permukiman kumuh. Seperti yang terjadi di daerah Angke, Tambora, Jakarta Barat dimana sebagian besar area di sekitar sungai difungsikan sebagai rumah hunian (sebagian rumah non- permanen). Dengan keterbatasan lahan dan tingginya tingkat pemenuhan kebutuhan mengakibatkan daerah ini tidak memiliki ruang publik yang mencukupi untuk memfasilitasi kawasan ini.

Perencanaan kota/pemukiman tidak akan terlepas dari pentingnya aksesi-bilitas terhadap pembangunan sebuah kawasan. Aksesibilitas yang didukung dengan konektivitas yang baik diyakini sebagai salah satu komponen terpenting pembentuk kota yang baik karena tidak hanya menghubungkan ruang dengan sekitarnya, tapi juga menghubungkan pengguna dan ruang. (Carr et al.,1992; Jacobs, 1961; Jacob \& Appleyard, 1987; Lynch, 1981; Salingaros, 1999 dikutip Sik, Heng, and Trivic 2016). Hal ini menunjukkan bahwa faktor aksesibilitas sebuah kawasan sangat berpengaruh terhadap ikatan antar ruang, lingkungan, dan pengguna. Selain itu, aksesibilitas yang baik memungkinkan aktivitas sementara dan aktivitas jangka lama untuk terjadi (Gehl, 1996; Lynch 1960 dikutip Sik, Heng, and Trivic 2016). Hal ini menunjukkan bahwa terdapat hubungan antara kualitas aksesibilitas dengan intensitas aktivitas luar.

Penelitian ini memfokuskan pada rumusan berikut:

1. Apa kriteria pendukung aksesibilitas ruang publik?

2. Bagaimana kriteria pendukung aksesibilitas ruang publik dapat terintegrasi dengan sungai?

Tujuan dalam penulisan makalah ini adalah untuk mengetahui kriteria apa saja pada ruang publik sehingga mendukung aksesibilitas di bantaran sungai dan meningkatkan akitivitas di dalamnya. Dalam menguji teori ruang publik yang akan diteliti ialah ruang publik Kalijodo dalam melihat kriteria pendukung aksesibilitas terhadap bantaran sungai. 


\section{Metode Penelitian}

Teori yang dibutuhkan ialah teori mengenai tepian sungai dimana pembahasan mengenai jenis dari tepian sungai berdasarkan bentukannya, definisi, fungsi, dan elemen pembentuk ruang publik yang akan dikaitkan dengan teori Placemaking. Dari tabulasi teori akan dibahas mengenai karakteristik aksesibilitas yang baik pada kawasan tersebut sehingga terlihat keterkaitan dengan jenis aktivitas penduduk.

\section{Hasil dan Pembahasan}

\section{Integrasi Sungai}

Berdasarkan Charles A. McLaren dalam jurnal A Guide to Riverfront Development terdapat beberapa prinsip yang harus diperhatikan dalam merancang perkembangan kawasan yang terintegrasi pada sungai, antara lain:

1. Membentuk riverfront sebagai ikon baru kota/kawasan;

2. Menunjukkan nilai sejarah sungai tersebut;

3. Mengaktifkan daerah tepian sungai 4. Mengurangi hambatan di sekitar sungai dan mengkoneksikan kembali dengan sungai;

5. Melibatkan elemen air pada sungai terhadap aktivitas kawasan;

6. Menghubungkan kembali sungai dengan daerah tepian serta lingkungan penduduk;

7. Memperbaiki dan meningkatkan kualitas lingkungan air;

8. Menerapkan prinsip desain berkelanjutan dalam pemilihan material yang baik.

\section{Public Space}

Stephen Carr dalam bukunya Public Space menyatakan ruang publik sebagai suatu fasilitas/wadah tempat berlangsungnya kehidupan komunal sebuah kawasan. Ruang-ruang ini dapat berupa jalan, taman, plaza, alun-alun yang bertindak sebagai wadah untuk menampung flow dan pergerakan manusia. Ruang dinamis ini berperan dalam memberi alur pergerakan yang baik, bertindak sebagai pusat berkumpulnya interaksi antar orang, dan sebagai wadah penampung kegiatan bermain dan bersantai. (Carr 1992).

Dilihat dari perkembangannya, ruang publik telah mengalami revolusi dari zaman ke zaman dan memberikan manfaat besar bagi kehidupan komunal sebuah kawasan. Perkembangan ini menjadikan ruang publik dapat terbagi menjadi beberapa tipe dengan karakteristiknya masing-masing (Carr 1992) antara lain seperti taman kota, plaza, pasar, jalan, ruang komunitas, waterfront, dll.

Dalam mencapai suatu lingkungan publik yang responsif terhadap penggunanya, terdapat lima kebutuhan utama yang dicari seorang dalam mencapai kepuasannya di ruang publik (Carr 1992), yaitu:

\section{Comfort}

Merupakan kebutuhan utama yang mendorong seorang untuk mau menggunakan/berdiam dalam sebuah ruang publik. Indikator kenyamanan dapat dilihat dari seberapa lama orang menggunakan tempat tersebut. Beberapa faktor yang mempengaruhi tingkat kenyamanan seorang dalam sebuah tempat adalah faktor lingkungan (cuaca, angin, sinar matahari), kenyamanan fisik (penyediaan fasilitas yang memadai), 
dan kenyamanan sosial-psikologis (suasana tempat yang tenang dan aman).

\section{Relaxation}

Merupakan pemenuhan kebutuhan yang mencakup kenyamanan secara psikis (pikiran). Untuk mencapai kebutuhan ini di lingkup kota, elemen ekologis seperti pepohonan, tumbuh-tumbuhan, fitur air dapat menjadi faktor kontras yang dapat memudahkan seorang untuk bersantai.

\section{Passive Engagement}

Adalah kebutuhan seorang untuk menikmati lingkungan sekitar tanpa terlibat interaksi langsung dengan user lainnya. Elemen yang dapat mendukung terciptanya passive engagement dapat berupa pertunjukan, view yang menarik, aktivitas orang sekitar,dll.

\section{Active Engagement}

Adalah kebutuhan seorang yang melibatkan pengalaman langsung dengan tempat dan orang didalamnya. Bentuk kebutuhan ini berupa interaksi sosial yang mana melibatkan kontak langsung, baik dengan teman, keluarga, maupun orang asing. Pengaturan tempat duduk, patung, air mancur dapat mempengaruhi terciptanya situasi kondusif untuk interaksi sosial.

\section{Discovery}

Adalah keinginan akan mencoba pengalaman baru yang disediakan dalam sebuah tempat. Bentuk kebutuhan seperti ini dapat berupa konser, festival, pameran seni, teater, pasar, aktivitas kemasyarakatan,dll yang biasanya bersifat musiman.

Sebuah ruang publik dapat dikatakan berfungsi dengan baik ketika orang banyak berdatangan untuk menggunakan tempat tersebut. Ruang publik pada dasarnya merupakan sebuah lingkungan yang bebas, orang dapat memilih untuk mau menggunakannya atau mungkin memilih untuk pergi ke tempat lain. Dalam buku The Project for Public Space dikatakan bahwa terdapat beberapa atribut yang harus diperhatikan dalam membentuk ruang publik yang baik (Project 1999 dikutip

Carmona et al.2010) antara lain:

\section{Comfort and Image}

Pengaturan atribut fisik dalam ruang publik secara terperinci/mendetail dapat memberikan kenyamanan kepada seorang. Penyusunan bangku, penyediaan toilet, rak sepeda, pohon sebagai peneduh merupakan contoh aspek-aspek yang dapat mendukung ikatan seorang terhadap sebuah tempat.

\section{Access and Linkage}

Tempat yang baik adalah tempat yang mudah dilihat dan mudah dijangkau. Daya tarik visual terhadap sebuah tempat sangat mempengaruhi kemauan seorang untuk pergi ke tempat tersebut. Orang cenderung ingin mengetahui hal apa yang ditawarkan tempat tersebut. Begitu pula dengan akses, jika ruang publik tidak menyediakan akses yang baik bagi seorang untuk mencapai tempat tersebut/ melewati jalanan yang berbahaya untuk disebrangi maka ruang publik tersebut tidak akan banyak dipakai.

\section{Uses and Activity}

Atribut ini membahas mengenai kegunaan dan aktivitas apa yang ditawarkan sebuah ruang publik kepada penggunanya. Semakin beragam aktivitas yang ditawarkan sebuah tempat, maka semakin tinggi pula 
peluang tempat tersebut untuk dikunjungi orang karena ada banyak hal yang dapat dilakukan pada tempat tersebut. Aktivitas dan kegunaan disini dapat dijadikan sebagai anchor program untuk mengikat daya tarik seorang.

\section{Sociability}

Ruang publik harus baik harus dapat menampung kegiatan sosial. Di tengah kepadatan aktivitas sehari-hari, kebutuhan seorang akan hal-hal sosial juga harus diperhatikan, seperti mengamati pemandangan, bertemu teman, melakukan interaksi dengan orang lain.

Dari pemikiran Carmona dan Carr mengenai ruang publik, dapat disimpulkan bahwa elemen-elemen yang harus diperhatikan dalam membentuk ruang publik yang baik adalah kenyamanan (Comfort), aktivitas (uses and activity), akses (access) dan daya tampung kegiatan sosial (sociability).

Tabel 1. Relasi kriteria ruang publik

\begin{tabular}{|c|c|c|}
\hline $\begin{array}{l}\text { Stephen } \\
\text { Carr Public } \\
\text { Space }\end{array}$ & \begin{tabular}{ll}
\multicolumn{2}{l}{ Carmona } \\
Public & Space \\
and & Urban \\
Spaces & \\
\end{tabular} & Kesimpulan \\
\hline Comfort & Comfort Image & Comfort \\
\hline Relaxation & $\begin{array}{l}\text { Uses and } \\
\text { Activity }\end{array}$ & Activity \\
\hline $\begin{array}{l}\text { Passive } \\
\text { Engagement }\end{array}$ & Access Linkage & Access \\
\hline $\begin{array}{l}\text { Active } \\
\text { Engagement } \\
\text { Discovery }\end{array}$ & Sociability & Sociability \\
\hline
\end{tabular}

\section{Aksesibilitas Ruang Publik}

Menurut Salingaros (1999), ruang kota yang baik memprioritaskan pejalan kaki dengan menyediakan berbagai jalur pejalan kaki yang mudah diakses, dibedakan dari jalur non-pejalan kaki, dan dirancang sesuai dengan standar universal agar dapat digunakan oleh seluruh kelompok pengguna (Sik, Heng, and Trivic 2016). Faktor-faktor yang harus diperhatikan untuk menciptakan kualitas ruang kota yang aksesibel terhadap pejalan kaki antara lain:

\section{Pedestrian Access Points}

Akses pejalan kaki yang baik merupakan salah satu faktor penting bagi ruang kota untuk dapat berfungsi dengan baik (Whyte 1980 dikutip Sik, Heng, and Trivic 2016). Aksesibilitas yang baik memungkinkan aktivitas sementara dan aktivitas jangka lama untuk terjadi (Gehl, 1996; Lynch 1960

dikutip Sik, Heng, and Trivic 2016). Akses pejalan dapat berupa akses formal maupun akses informal. Akses formal berupa akses utama dan akses langsung dalam sebuah kawasan sedangkan akses informal adalah akses

yang memberikan pilihan pada penggunanya, biasanya akses seperti ini dapat dijumpai pada jembatan dan jalur bawah tanah. Perencanaan ini akan penting karena berkaitan dengan pencapaian seorang pada sebuah tempat.

\section{Universal Access}

Akses pejalan haruslah dapat dinikmati oleh semua orang tanpa terkecuali. Hal yang harus diperhatikan adalah kenyamanan dan keamanan bagi penggunanya, termasuk untuk orang tua, anak-anak, ibu hamil, ataupun kaum disabilitas.

\section{Types and Distribution of Universal Access}

Akses yang beragam dapat meningkatkan kemauan seorang untuk berjalan (Levine 2003). Distribusi akses 
dapat berupa ramp, horizontal pedestrian, ataupun tangga.

\section{Prioritizing the Pedestrian}

Faktor ini membicarakan mengenai prioritas jalur pejalan daripada jalur kendaraan dengan memperhatikan faktor keamanan. Salah satu contoh penerapannya adalah dengan memberikan batasan antar akses pejalan dan kendaraan.

Kesimpulan teori sementara, berdasarkan Stephen Carr, Carmona, Cho Im Sik, Martin Prominski dan Charles A. McLaren maka dalam meneliti aksesibilitas dan kualitas ruang publik di tepi sungai, hal yang perlu di analisis adalah kenyamanan, akses (mencakup akses visual, fisikal, pedestrian dan universal), aktivitas, sosiabilitas dan integrasi terhadap sungai.

\section{Analisis Aksesibilitas Ruang Publik di Kalijodo}

Kalijodo merupakan sebuah ruang publik (RPTRA) yang terletak di daerah Penjaringan, Jakarta Utara. Dilihat malamnya sebelum akhirnya dilakukan penertiban dan menjadikan daerah ini sebagai ruang publik. Dilihat secara konteks lokasi Kalijodo merupakan area yang terletak pada jalur hijau kota dan diapit oleh dua sungai, yaitu sungai Angke dan sungai Kerendang.

Fungsi ruang publik ini merupakan ruang publik rekreasional dimana ruang publik ini berfokus pada programprogram yang berkaitan dengan olahraga. Tempat ini biasanya banyak dikunjungi pada pagi dan sore hari dimana orang biasa melakukan kegiatan olahraga seperti bersepeda, skateboard, lari, senam dan kegiatan kuliner (makan pada tenda-tenda penjual makanan).

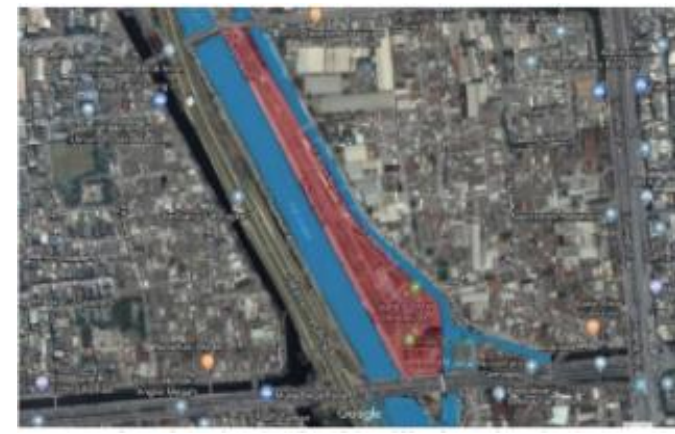

Gambar 1. Siteplan Kalijodo

Sumber: Diolah dari google earth, 2018
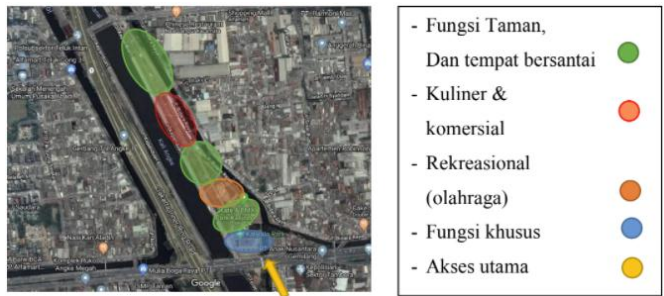

Gambar 2. Pembagian program Kalijodo

Sumber: Diolah dari google earth, 2018

\section{Comfort}

Kawasan Kalijodo dilihat pelindung dari matahari menggunakan shelter dan juga vegetasi. Vegetasi terdapat di sepanjang bagian yang bertemu dengan fitur air. Sedangkan, peneduh atau shelter hanya terdapat pada satu bagian saja (ditunjukkan pada warna merah di Gambar 3). 

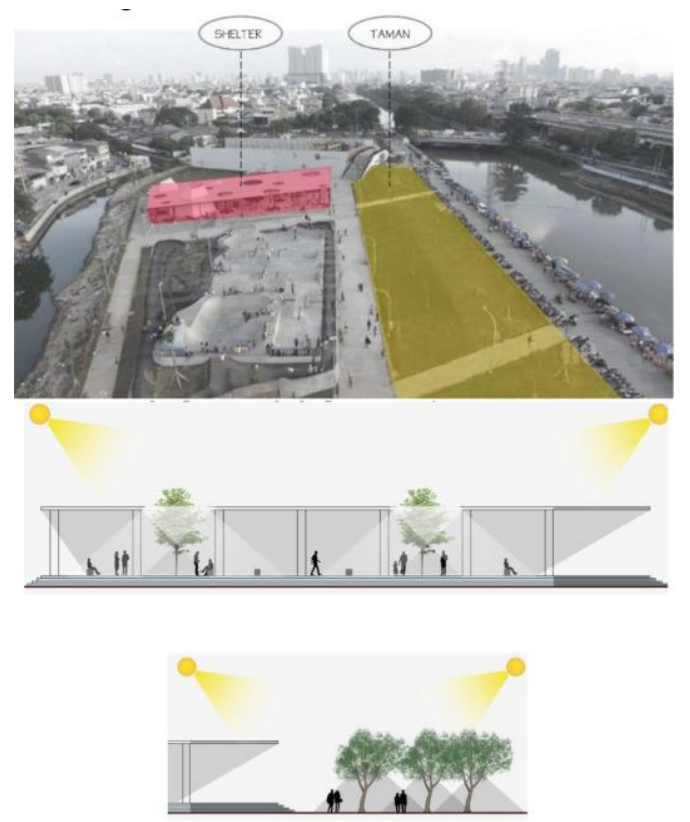

Gambar 3. Keveradaan shelter dan vegetasi

Terjadi permasalahan karena peneduh dan vegetasi tidak merata sehingga kenyamanan pada kawasan kurang berfungsi dengan baik pada ruang publik melihat cuaca pada kawasan yang terik sepanjang hari. Hal ini mengakibatkan aktivitas pada di siang hari kurang merata karena kurang adanya pelindung dari sinar matahari dan pada akhirnya terjadi perbedaan pemetaan aktivitas yang jauh dari siang ke malam hari.

Hal ini membuktikan bahwa keberadaan vegetasi dan shelter mempengaruhi aksesibilitas baik di dalam kawasan maupun dari luar kawasan. Pengunjung mempunyai kecenderungan untuk memngakses beberapa tempat yang teduh, hal ini terlihat pada akses di kawasan Kalijodo yang seharusnya menghubungkan dan interaksi terhadap sungai menjadi minim karena kurangnya faktor kenyamanan.

Penyebaran fasilitas penerangan yang terpusat mengakibatkan orang berkumpul di beberapa titik (yang memiliki tingkat penerangan yang baik) yaitu pada shelter, skatepark, dan area komersial. Seharusnya penyebaran lampu dibuat merata/tersebar (Gambar 4).
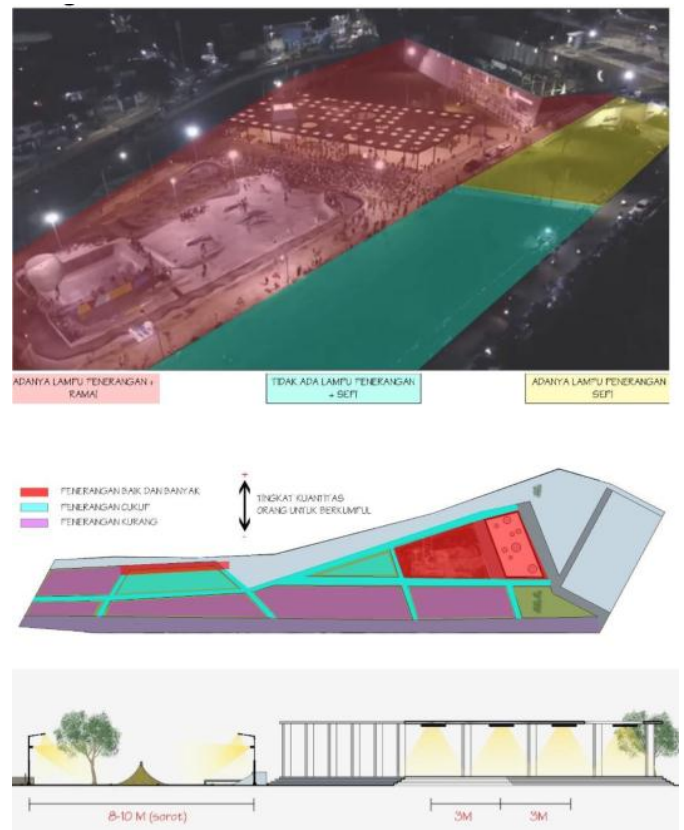

Gambar 4. Penerangan

Dari segi kenyamanan juga melihat keamanan fisikal maupun visual. Pada kasus ruang publik Kalijodo dengan kurangnya keamanan fisikal membuat pejalan kaki sulit untuk mengakses kawasan. Transportasi dan juga ruang gerak manusia kurang ada pembatas yang jelas. Secara visual, ruang publik kurang mempunyai keamanan dan juga kenyamanan karena semua masi terletak pada level yang sama dan akses kurang terlihat secara jelas dari titik pandang terutama di seberang sungai.

Berdasarkan permasalahan tersbeut, untuk memenuhi kriteria kenyamanan maka ruang publik Kalijodo dapat menerapkan keamanan fisikal berupa pembagian akses manusia dan transportasi, juga adanya batasan 
terhadap tapak. Sedangkan keamanan visual dapat berupa perbedaan kontur.
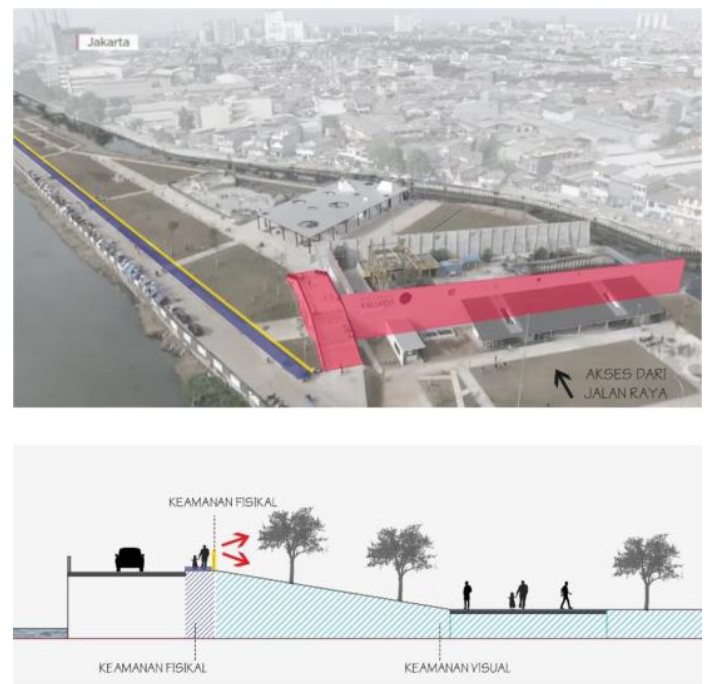

Gambar 5. Analisis keamanan

Access

Adanya pembagian akses manusia dan transportasi juga perhatian untuk akses bagi penyandang disabilitas ( $\mathrm{ramp}$ ) menjadikan akses fisikal baik namun boundary/batasan yang besar menjadikan orang luar tidak mendapatkan akses visual yang baik.
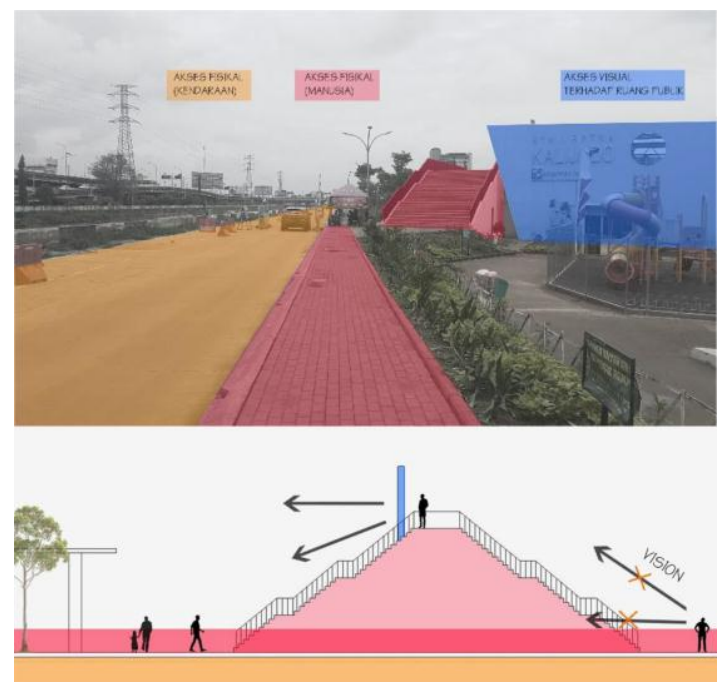

Gambar 6. Akses visual dan akses fisikal
Buruknya faktor keamanan dalam pencapaian seorang terhadap kawasan dapat mempengaruhi kemauan seorang untuk menggunakan tempat tersebut.

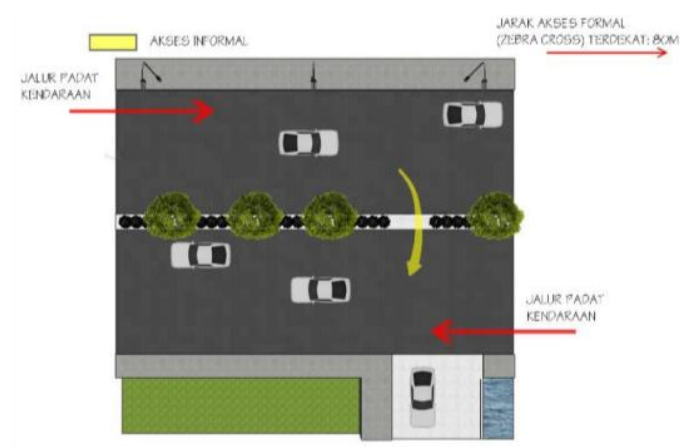

Gambar 7. Akses pedestrian

Pencapaian terhadap site menggunakan akses ramp sehingga memungkinkan semua orang untuk dapat menggunakan kawasan secara menyeluruh sekaligus meningkatkan peluang orang untuk datang. Tidak adanya keragaman akses vertikal pada kawasan menja-dikan orang tidak banyak menggu-nakan ruang yang tidak memiliki fungsi khusus (contohnya: taman).

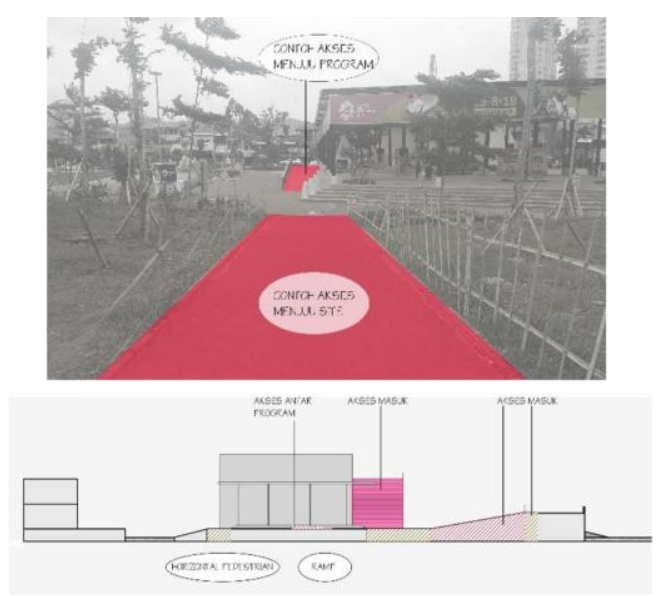

Gambar 8. Akses universal

Activity

Titik penyebaran aktivitas tidak merata dikarenakan banyak ruang yang tidak 
memiliki program sehingga kurang dapat menarik kemauan orang untuk menggunakannya. Ruang fleksibel yang banyak dan infrastruktur yang tidak memadai menyebabkan penyebaran aktivitas terpusat.

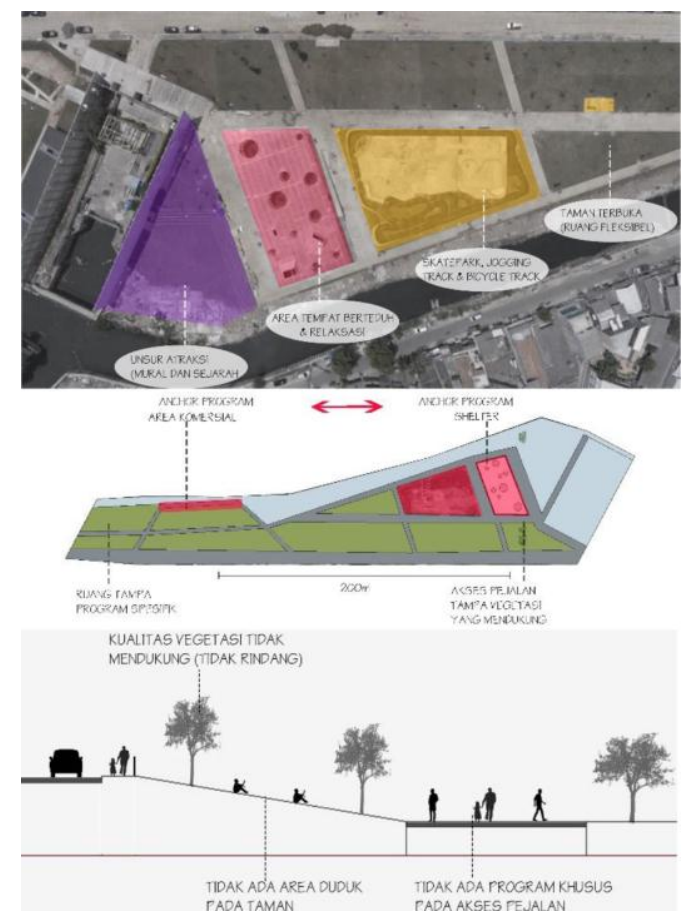

Gambar 9. Diagram aktivitas

\section{Sociability}

Leveling tanah dapat berfungsi sebagai pembatas antar 2 area yang membentuk rasa privat. Konektivitas sungai terhadap ruang publik dapat dijaga dengan menghilangkan batasan visual ataupun fisikal antar ruang publik dengan sungai.

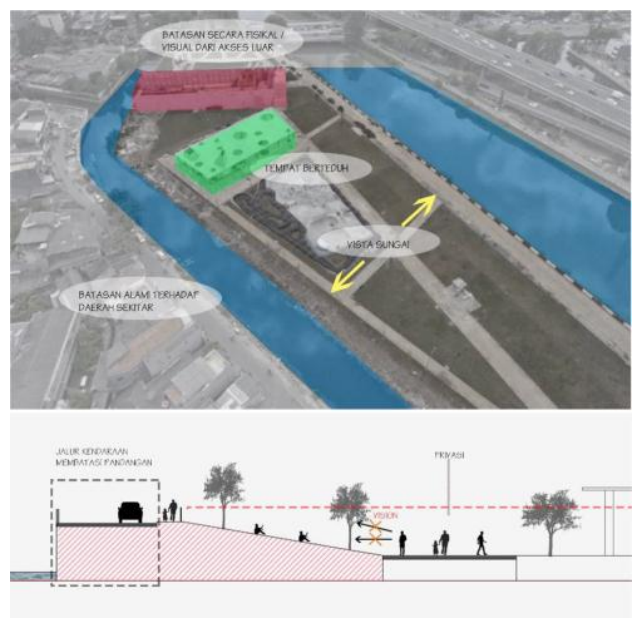

Gambar 10. Sosiabilitas

\section{Integrasi terhadap Sungai}

Hubungan antar ruang publik dan area komersial/residensial dipisahkan oleh sungai sebagai pembatas alami dengan perbandingan $\pm(4: 1)$. Penyediaan akses berupa jembatan juga menjadikan ruang publik ini erat kaitannya dengan penduduk sekitar.

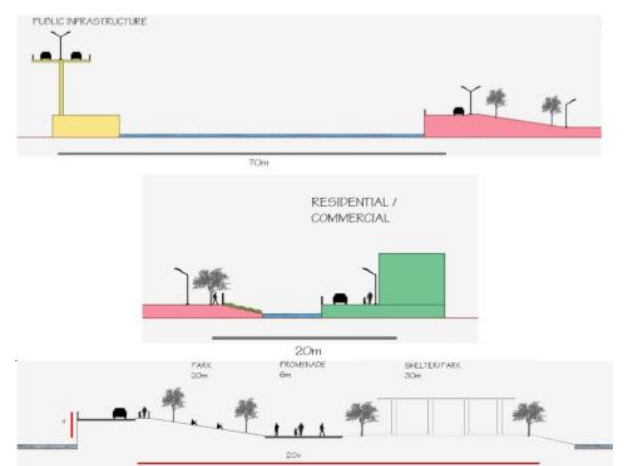

Gambar 11. Relasi ruang dan lingkungan

Sebuah ruang/kawasan harus menyediakan fasilitas yang mendukung manusia dalam melakukan aktivitasnya. Skala antar ruang pengguna tidak melebihi perbandingan 1:10 (agar tidak merasa terbatasi). Kualitas akses pejalan harus memiliki kualitas yang baik pada transisi akses jalan raya maupun transisi akses vertikal pada kawasan. 


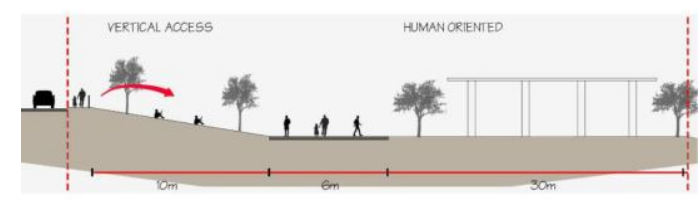

Gambar 12. Diagram walkable

Konektivitas antara ruang publik dan sungai dapat terjadi jika tidak ada batasan/boundary antar kedua area. Konektivitas ruang publik-sungai juga dapat terjadi ketika terdapat aktivitas yang melibatkan manusia dengan air.

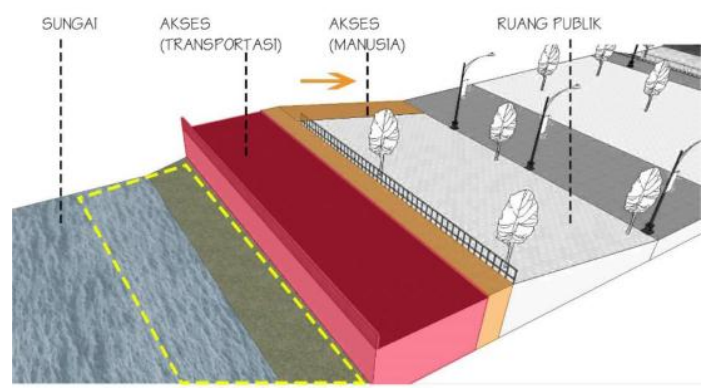

Gambar 13. Konektivitas air dan kawasan

Penempatan akses yang berorientasi tidak pada pejalan kaki dan tidak adanya ruang beraktivitas pada tepian sungai menyebabkan user dituntun untuk melakukan aktivitas pada ruang publik tanpa adanya keterkaitan dengan sungai.

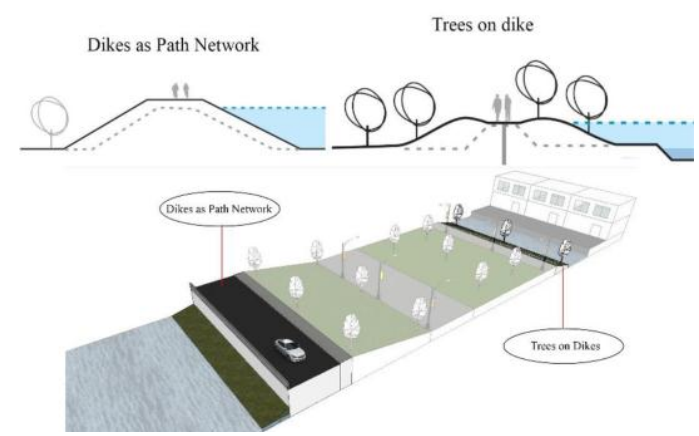

Gambar 14. Hubungan sungai dengan tepian sungai

\section{Kesimpulan dan Saran}

Berdasarkan hasil penelitian, kriteria kenyamanan Kawasan Kalijodo masih memerlukan adanya pemerataan terhadap vegetasi terutama pada setiap bagian akses untuk memudahkan pengunjung bergerak di dalam tapak. Kriteria aktivitas mempunyai kelemahan dengan tidak meratanya pemetaan kegiatan di dalam tapak sehingga kegiatan menjadi terlalu terpusat. Hal ini juga disebabkan dengan tidak adanya program yang spesifik pada tiap titiktitik di kawasan. Kriteria sosiabilitas tercapai dengan adanya perbedaan kontur sehingga membedakan tapak dan daerah di luar kawasan. Hal ini menciptakan perbedaan antara area di luar kawasan dan area publik di dalam kawasan. Kriteria akses visual tidak tercapai dikarenakan terdapat tangga yang menghalangi sehingga aktivitas di dalam ruang publik kurang terlihat, namun kehadiran tangga tersebut sebenarnya menunjang secara akses fisikal, harusnya dapat menggunakan material yang lebih transparan atau struktur berupa rangka sehingga tidak menghalangi secara visual.

Jika dilihat pada kriteria terakhir pada integrasi pada sungai kurang terpenuhi karena kurang adanya kegiatan yang berdekatan langsung dengan sungai. Meski terdapat jembatan untuk mengakses ke ruang publik melalui sungai, orientasi hanya di tujukan kepada ruang publik namun terpisah dari sungai karena adanya pemisah berupa akses transportasi.

Berdasarkan hasil dari penilaian terhadap kriteria ruang publik Kalijodo dalam mendukung aksesibilitas dan peningkatan aktivitas dapat dicapai melalui akses visual sehingga 
mengundang ketertarikan kepada pengunjung luar ke dalam kawasan. Penggunaan kontur juga dapat diaplikasikan agar dapat membedakan terhadap transportasi di area batas kawasan dengan kegiatan di kawasan Kalijodo sendiri. Pemetaan program dapat dilakukan secara merata dan kegiatan yang lebih spesifik agar aktivitas tetap tersebar, namun tetap harus didukung dengan adanya kenyamanan dengan penggunaan vegetasi yang lebih rapat sebagai pelindung dari matahari.

\section{Daftar Pustaka}

Carmona, Matthew, Tim Heath, Steve Tiesdell, and Taner Oc. (2010). Public Places, Urban Spaces: The Dimensions of Urban Design Second Edition. London: Routledge.

Carr, S., Francis, M., Rivlin, L.G. and Stone, A.M. (1992), Public Space. Cambridge University Press, Cambridge.

Gehl, Jan. (1987). Life Between Buildings: Using Public Space. Danish: Arkitektens Forlag.

McLaren, Charles A. (2000). Riverfront Design Guidelines.

Prominski, Martin. (2017). River.Space.Design: $\quad$ Planning Strate-gies, Methods and Projects for Urban Rivers. Second and enlarged edition. Basel ; Boston: Birkhäuser.

Sik, Cho Im, Chye Kiang Heng, and Zdravko Trivic. (2016). Re-Framing Urban Space, Urban Design for Emerging Hybrid and High-Density Condition. New York: Routledge. 
Jurnal Teknik Arsitektur ARTEKS, Volume. 2, Nomor 2, Juni 2018 ISSN 2541-0598 